https://helda.helsinki.fi

\title{
Value change in men and women entering parenthood: New mothers' value priorities shift towards Conservation values
}

\section{Lönnqvist, Jan-Erik}

2018-01-01

Lönnqvist , J-E , Leikas , S \& Verkasalo , M 2018 , ' Value change in men and women entering parenthood : New mothers' value priorities shift towards Conservation values ', Personality and Individual Differences, vol. 120 , pp. 47-51 . https://doi.org/10.1016/j.paid.2017.08.019

http://hdl.handle.net/10138/304732

https://doi.org/10.1016/j.paid.2017.08.019

cc_by_nc_nd

acceptedVersion

Downloaded from Helda, University of Helsinki institutional repository.

This is an electronic reprint of the original article.

This reprint may differ from the original in pagination and typographic detail.

Please cite the original version. 
2 Value Change in Men and Women Entering Parenthood: New Mothers' Value Priorities Shift 3 towards Conservation Values

4

5 Running head: Value Change

6

7

8

9

10

11

12 Word count: 5000

13 


\section{Abstract}

3 There is little research on how life transitions influence value priorities. Our purpose was to

4 investigate, within the framework provided by Schwartz' Values Theory, the effects of

5 entering parenthood on personal values. Study $1(N=12850)$, employing cross-sectional

6 European Social Survey data, showed that Finnish mothers, as compared to non-mothers,

7 were closer to the Conservation pole of the value dimensions that opposes Conservation

8 values with Openness to Change values. Study 2 longitudinally followed Finnish couples ( $N$

9 =292) entering parenthood from the first weeks of pregnancy to three months after

10 childbirth. Both self- and spouse-ratings of values showed that new mothers' value priorities

11 shifted towards Conservation values. New mothers perceived a similar shift in new fathers'

12 personal values, but no changes occurred in men's self-ratings. Neither study suggested

13 change on the value dimension that opposes Self-Transcendence values with Self-

14 Enhancement values. Across the cross-sectional and longitudinal designs, and across self-

15 and spouse-ratings of values, our results consistently suggest that new mothers' shift their

16 value priorities in the direction of increased Conservation over Openness to Change. These

17 results are consistent with the notion that value change may facilitate adaptation to life 18 events.

21 Keywords: Schwartz' Values Theory; Value Change; Personal Values; Parenthood; Sex

22 Differences 

towards Conservation Values

5 Entering parenthood, widely regarded as one of the most definitive stages of life, has been

6 documented to have a plethora of psychological consequences. However, there is almost no

7 empirical research on how parenthood influences our values; that is, what we think of as

8 important in our lives. We explored the associations between parenthood and values within

9 the framework provided by Schwartz' (1992) Values Theory. First, in a nationally

10 representative sample of Finns, we compared the values of parents and non-parents. Second,

11 in a longitudinal study on Finnish parents-to-be we investigated how values change from the

12 onset of pregnancy to three months after childbirth.

\section{$13 \quad 1.1$ Values}

14 Values tend to be defined as abstract ideals that serve as guiding principles in people's lives.

15 Typical examples of values considered highly important - both as prescriptive principles and

16 as intrinsically valuable ideals - are equality, freedom, and helpfulness. Much of the most

17 recent research on value priorities employs the framework provided by Schwartz' (1992)

18 Values Theory. Based on his review of the prior literature, Schwartz (1992) defined values as

19 self-imposed criteria that help maintain a delicate balancing act between basic motives that

20 arise from our needs as individuals and as members of larger social groups. Schwartz

21 proposed that these motives can, more or less universally, be organized along the two

22 dimensions depicted in Figure 1. 
2 Self-Transcendence values (Universalism and Benevolence) with Self-Enhancement values

3 (Achievement and Power; see, e.g., Schwartz, 1992; Verkasalo, Lönnqvist, Lipsanen, \&

4 Helkama, 2009). The Self-Transcendence values emphasize acceptance of others as equals

5 and concern for their wellbeing, whereas the Self-Enhancement values emphasize own

6 relative success and control over others. The second axis opposes Conservation values

7 (Conformity, Tradition, Security) with Openness to Change values (Self-Direction and

8 Stimulation). The Conservation values emphasize self-restriction, preservation of traditional

9 practices, and protection of stability, whereas the Openness to Change values emphasize own

10 independent thought and action and favor change. The tenth value, Hedonism, is located

11 between the Openness to Change and the Self-Enhancement poles. This structure follows

12 from the fact that action in pursuit of any value has consequences that conflict with some

13 values but are congruent with others.

As noted by Maio (2010), values overlap with other constructs - goals, attitudes,

15 and personality traits - that are currently more dominant in personality psychology: (1)

16 values and goals express basic human motivations, (2) values and attitudes are evaluative,

17 and (3) values and traits are at least somewhat stable over time and situations. Values thus

18 have something in common with all three constructs (for a review on the empirical research

19 on these connections, see Maio, 2010), but cannot be reduced to any one of these constructs.

\section{$20 \quad 1.2$ Value Change}

Value change has typically not attracted the interest of psychologists. One reason for

22 this may be the high test-retest reliabilities obtained with values questionnaires (Bardi, Lee, 
1 Hoffman-Towfigh, \& Soutar, 2009). High rank-order stability; that is, individuals

2 maintaining their positions relative to each other, does not, however, exclude the possibility

3 of mean-level change. A group of people may change in the same direction while maintaining

4 their order on the relevant dimension. Some empirical results are indeed suggestive of mean-

5 level change across the life-course. One method to study this issue has been to correlate age

6 with values. For instance, employing European Social Survey data, Verkasalo et al. (2009)

7 showed that Conservation and Self-Transcendence values are more important in older age

8 groups. However, a recent longitudinal study on value development over the life span

9 suggests that these effects may in part be cohort effects rather than developmental effects

10 (Milfont, Milojev, \& Sibley, 2016), emphasizing the need for more longitudinal studies.

11 There is overall very little longitudinal research on value change, and especially little 12 on whether major life-transitions can produce value change. One of the few exceptions is a

13 longitudinal study by Bardi and colleagues (2009) in which the extent of life changing events

14 (e.g., death of a spouse, change to different line of work, marriage) that participants

15 experienced during a two-year period was positively associated with greater overall intra-

16 individual value change. Presenting a theoretical model in which environmental primes may

17 either with or without our awareness activate certain values and lead to value change, Bardi

18 and Goodwin (2011) argued that "if the same concept is primed repeatedly by a new life

19 situation (e.g., parenthood) or by the environment (e.g., a new culture) a more permanent

20 change in values may take place" (p. 277). Such change, they argued, "facilitated adapting to

21 living in a new country and adapting to parenthood" (p. 278). 
The little empirical research on the specific life-transitions that could elicit

2 value change has indeed identified migration as a context in which values may change in a

3 predictable manner. In a sample of Ingrian-Finnish migrants from Russia to Finland, the

4 importance of both Universalism and Security values increased after migration, whereas the

5 importance of Power and Achievement values decreased (Lönnqvist, Jasinskaja-Lahti, \&

6 Verkasalo, 2011). These changes were such that they could, consistent with the arguments set

7 forth by Bardi and Goowin (2011), be interpreted as facilitating adjustment. The notion that

8 value change is adaptive was also put forth by Gouivea, Vione, Milfont, and Fischer (2015).

9 Building on the functional theory of human values (Gouveia, Milton, \& Guerra, 2014),

10 Gouivea et al. (2015) argued that age differences in values across the life-span are consistent

11 with theories on adaptive aging - values may serve different adaptive functions at different

12 developmental stages. For instance, existence values, such as stability and survival, could be

13 expected to become more important upon entering parenthood because parents have to take

14 care of the survival of their offspring.

\section{$15 \quad 1.3$ Sex Differences in Value Change}

Value change cannot be assumed to be uniform across men and women

17 (Gouveia et al., 2015). A study by Ferriman, Lubinski and Benbow (2006) - to the best of our

18 knowledge the only previous study to have longitudinally investigated how parenthood

19 changes values - reported on very different effects for men and women. In a sample of

20 profoundly gifted individuals, the study replicated the typical finding that for women,

21 relatively to men, family, friends, and social well-being outside of work tended to be more

22 dominant life themes. More pertinent to the present research, the study reported larger gender 
1 differences among parents than among non-parents. Men with and without children

2 responded very similarly to most items. Women, by contrast, showed more variation. The

3 responses of the non-parent women were more similar to the responses of men than to the

4 responses of mothers. Whereas men and non-parent women had a more agentic, competitive

5 and individualistic perspective, women with children favored a more communal, holistic

6 perspective, which emphasized community, family, and friendships.

The above results are consistent with a recent longitudinal study by Milfont et

8 al. (2016) on the life-span development of values, according to which women show higher

9 temporal variability in Conservation values. The authors suggested that women are expected

10 to play different social roles at different points in life, including taking on the majority of

11 parenting and housekeeping tasks, which are inherently somewhat protective and

12 conservative. Such distinct social roles, less likely to pertain to men, may temporarily affect

13 the importance women attribute to Conservation values.

The more general literature on the impact of parenthood on men and women

suggests that parenthood continues, even in the current age of supposed gender equality, to shape the lives of men and women in very different ways. Most pertinent to the present research, parenthood typically reinforces traditional gender roles and behaviours (Baxter,

18 Buchler, Perales, \& Western, 2014; Katz-Wise, Priess, \& Hyde, 2010). In terms of values,

19 and given that parenthood would be expected to have more of an impact on women (Ferriman

20 et al., 2006; Gouveia et al., 2015; Milfont et al., 2016), this implies that women could be expected to emphasize existing sex differences by shifting further towards the Conservation 
1 and Self-Transcendence poles of the two value dimensions (Schwartz \& Rubel, 2005;

2 Verkasalo et al., 2009).

\section{1.4. Purpose of the present research}

4

The purpose of the present research was to investigate how entering parenthood changes the personal values of men and women. In Study 1, which was cross-sectional by design, we employed European Social Survey data to investigate whether Finnish parents and non-parents had different value priorities. We expected mothers, as compared to nonmothers, to be closer to the Conservation and Self-Transcendence poles of the two value dimension. We refrained from predictions regarding men.

\section{In Study 2 we longitudinally followed Finnish couples entering parenthood}

from the beginning of pregnancy to three months after childbirth. To validate and complement the self-report questionnaires, we also asked spouses to evaluate each other's values. Some recent research suggests that people can assess the values of those they know well with remarkable accuracy; self-other agreement for the values dimensions is around .50 (Dobewall, Aavik, Konstabel, Schwartz, \& Realo, 2014). To the best of our knowledge, Study 2 is the first research to employ other-ratings to the study of value change.

\section{Study 1}

\subsection{Method}

2.1.1 Participants and Procedure. The European Social Survey (ESS) is carried out every other year. For the present research, we employed Finnish data from rounds 1 to 7 (2002-20016). This gave us a total of 12850 respondents (6700 women), with a mean 
1 age of 48.20 years $(S D=18.60$; range $15-100)$. Of all respondents, 8478 (4516 women)

2 reported having lived in their own household with children (we interpreted this as indicating

3 parenthood), and 4280 (2130 women) reported never having had children live in their own

4 household. Those who did not respond to the question $(N=96)$ were excluded from all

5 analyses. Those who responded did not, in terms of personal values, differ from those that did

6 not respond.

Participants' level of education was coded on a five-point scale: less than lower secondary $(1 ; N=2088)$, lower secondary $(2 ; N=1759)$, upper secondary $(3 ; N=2559)$, post secondary $(4 ; N=1824)$, and tertiary $(5 ; N=4607)$. The 13 participants who failed to respond to this question were excluded from further analyses.

2.2.2 Measures. The ESS Human Values Scale, also known as the PVQ21, includes 21 items and is intended for use in large surveys with limited space (Schwartz, 2003). These item each offer a short portrait describing a person's goals, aspirations, and desires. Participants rate the extent to which the portrayed person portrayed is similar to themselves, using a 6-point response scale ranging from not like me at all to very much like me. For example, to measure power, the PVQ21 includes two portraits: "It is important to him to be rich. He wants to have a lot of money and expensive things" and "It is important to him to get respect from others. He wants people to do what he says." We used the equations provided by Verkasalo et al. (2009) to compute, using all 21-items, the two bipolar value dimensions that identify the two basic value conflicts: Conservation vs. Openness to Change and Self-Transcendence vs. Self-Enhancement. The General Reliability Coefficients (GRC; Tarkkonen \& Vehkalahti, 2005) of these two dimensions were .71 and .73, respectively. The 
1 Tarkkonen GRC is a statistical technique for assessing the reliability of composite scales. It

2 has some important advantages over the more commonly used Cronbach's alpha: (a) it

3 reports the exact internal consistency, and not the lower bound, as does Cronbach's alpha,

4 and (b) it does not make the same rigid assumptions about equal variances and correlations of

5 the items as does Cronbach's alpha, but includes both error variance and weights of factor

6 loadings.

\section{$7 \quad 2.2$ Results}

8 Age and educational level, both of which are robustly associated with both personal values

9 (Verkasalo et al., 2009) and with parenthood, were controlled for in all analyses, as well as

10 was the year that the data was collected. Among women, the partial correlations between

11 having had children and Conservation and Self-Transcendence values were $r_{\text {part }}(6634)=.091$

$12(p<.001)$ and $r_{\text {part }}(6634)=.069(p<.001)$, respectively. Mothers, as compared to non-

13 mothers, thus scored somewhat higher on both Conservation and Self-Transcendence values.

Among men, the partial correlations between having children and Conservation and Self-Transcendence values were $r_{\text {part }}(6097)=.008(p>.828)$ and $r_{\text {part }}(6097)=.040(p=$

16 .002), respectively. Fathers, as compared to non-fathers, thus scored somewhat higher on

17 Self-Transcendence values.

Two univariate GLMs were run to test the statistical significance of sex

19 differences. The interaction between sex and being a parent was statistically significant in the 20 prediction of Conservation over Openness to Change values $(F=21.52$, partial eta squared $=$ $21.002, p<.001)$ but not in the prediction of Self-Transcendence over Self-Enhancement values $22(F=1.47$, partial eta squared $=.000, p=.225)$. The association between parenthood and 
1 Conservation over Openness to Change values was thus stronger among women than among 2 men.

4 values between parents and non-parents are more strongly driven by differences at one pole

5 of the value dimension. For instance, it could be that although mothers, as compared to non-

6 mothers, score higher on Conservation values, they may not necessarily score lower on

7 Openness to Change values. Examining this issue is especially pertinent as the functional

8 theory of values (Gouveia et al., 2014; 2015) has recently challenged the notion of conflict

9 within the values system: all basic values could be expected to be congruent (positively

10 correlated) among mature individuals (cf. Schwartz, 2014). To investigate this issue, we

11 computed sum scores for Conservation (six Tradition, Security, and Conformity items),

12 Openness to Change (four Self-Direction and Stimulation items), Self-Transcendence (five

13 Universalism and Benevolence items) and Self-Enhancement (four Achievement and Power

14 items). Among women, the partial correlations between having had children and

15 Conservation, Openness to Change, Self-Transcendence and Self-Enhancement were $r_{\text {part }}$

$16(6634)=.067(p<.001),-.096(p<.001), .031(\mathrm{p}=.012)$, and $-.061(p<.001)$. The

17 associations between having had children and the two value dimensions were thus mirrored at

18 both poles of both dimensions, supporting the notion of conflict within the values system.

19 Among men, all effects were too small (all $\left.r_{\text {part }}(6097)<.045\right)$ to permit any conclusions.

\section{Study 2}

21 The cross-sectional results of Study 1 suggest, as expected, that mothers, as compared to non-

22 mothers, are closer to the Conservation pole of the valued dimension opposing Conservation 
1 values with Openness to Change values. This could be either due to the effects of childbirth

2 on values, or due to self-selection into parenthood - women scoring higher on Conservation

3 values may be more likely to become parents. Parents of both sexes were somewhat closer to

4 the Self-Transcendence pole of the dimension opposing Self-Transcendence values with Self-

5 Enhancement values, but the difference between parents and non-parents was too small to

6 serve as a reliable basis for further hypothesis development. In Study 2 we thus expected

7 women entering parenthood to move towards the Conservation pole of the value dimension

8 opposing Conservation values with Openness to Change values.

\section{$9 \quad 3.1$ Method}

3.1.1 Participants and Procedure. After a positive home pregnancy test,

11 potential parents-to-be in Finland are instructed to without delay contact a maternity and

12 child health guidance center. At their first appointment, usually scheduled in week eight of

13 the pregnancy, the parents-to-be discuss with a nurse topics such as the importance of good

14 nutrition and exercise during pregnancy, how the pregnant woman feels, and the

15 transformations that her body undergoes during pregnancy. During a three month stint in the

16 spring and summer of 2015, midwives in the Helsinki city area informed first-time parents-

17 to-be at their first appointment of the opportunity to take part in our longitudinal research.

18 Paper-and-pencil questionnaires along with two return envelopes (one for the mother-to-be,

19 one for the father-to-be) were posted to the parents-to-be along with the standard pregnancy

20 information booklet.

As an incentive to participate, couples were offered a professional-level family

22 portrait (worth around $100 €$ ) at completion of the follow-up (initially we offered raffle 
1 tickets for the family portraits, but decided at the follow-up stage to photograph everyone).

2 The questionnaires were sent to approximately 1000 couples. Out of these 1000 couples, 175

3 couples $(17.5 \%)$ returned both mother's and father's questionnaire (the rather low initial

4 response rate was most likely due to only raffle tickets being promised at this stage). Out of

5 these 175 couples, 146 couples $(83.4 \%)$ eventually completed the follow-up questionnaires

6 (the high retention rate was most likely due to everyone now being promised the family

7 portrait). These 146 couples served as our sample (a series of ANOVAs revealed no

8 differences between those who dropped out and those that did not). Only couples in which

9 both parents volunteered to participate were allowed to participate.

The follow-up was run in the summer of 2016. In the follow-up, participants

were called up at 6 weeks postpartum and asked whether they would like to complete the questionnaire electronically or have it posted home. After that, participants were sent reminders every two weeks until they replied, up until 6 months postpartum (146 couples out

14 of the original 175 had completed the follow-up questionnaire by then). On average, couples completed the follow-up questionnaire at 3.32 months postpartum ( $S D=2.00$ months). The mean age of female participants was 32 years $(S D=3.87$; range: $21-44)$, and the mean age of

17 male participants was 34 years $(S D=5.03$; range $=23-52$ years $)$.

\subsubsection{Measures. The Short Schwartz's Value Survey (SSVS; Lindeman and}

Verkasalo 2006) is specifically designed to measure the two bipolar value dimensions. It ask

the respondents to rate the importance of each of the ten basic values as life-guiding

21 principles. The response scale ranges from 0 Not important to 8 Very important. For example, to measure Universalism, the SSVS employs the item 'Universalism (broad-mindedness, the beauty of nature and the arts, social justice, a world at peace, equality'. We used the 
1 equations provided by Lindeman and Verkasalo (2006) to compute, using all ten items, the

2 two bipolar value dimensions. Participants completed the SSVS in both self- and spouse-

3 rating format. The reliability estimates are presented in Table 1.

\section{$4 \quad 3.2$ Results}

5 Table 1 shows descriptive statistics for the self- and spouse-ratings of values before and after

6 entering parenthood. Also shown are the results of paired samples $t$-tests testing for change in

7 personal values and the effect sizes of this change (the Cohen's $d$ s were computed from the

8 original means and standard deviations, not the $t$-tests; see Dunlap, Cortina, Vaslow, \&

9 Burke, 1996).

As expected, both self- and spouse-ratings of values indicated that women

11 moved towards the Conservation pole of the value dimension opposing Conservation values

12 with Openness to Change values. Self- and spouse ratings were also in agreement in that

13 neither women nor men changed in terms of the value dimension opposing Self-

14 Transcendence values with Self-Enhancement values. The only disparity between self- and

15 spouse-ratings concerned men's alleged change on the value dimensions opposing

16 Conservation values with Openness to Change values - women perceived their spouses to

17 have changed in the direction of greater Conservation, but men's self-ratings did not change.

\section{General Discussion}

Most parents would agree that having a child is one of the most profoundly life-

20 changing events. However, despite often being used as the prototypical example of the type

21 of event that would be expected to induce value change (e.g., Bardi \& Goodwin, 2011), there 
1 has been almost no empirical research on this topic. Our results suggest, as expected, that

2 women who have become parents, as compared to those who have not, are closer to the

3 Conservation pole of the value dimension that opposes Conservation values with Openness to

4 Change values (Study 1), and that this difference is associated with entering parenthood

5 (Study 2). The results regarding men were weak and inconsistent.

7 Transcendence values with Self-Enhancement values did not change meaningfully upon

8 entering parenthood - the effect sizes observed in Study 1 were very small and there were no

9 indications of change in Study 2. As parents focus more on their child's need and less on their

10 own lives and careers, they could have been expected to assign more importance to values

11 emphasizing the welfare of others (Self-Transcendence values). On the other hand, despite

12 the wide array of statutory public benefits aimed at defraying the cost of raising a child, doing

13 so is, even in Finland, rather expensive - based on 2001 price-levels, this cost was estimated

14 at $105000 €$ (Kartovaara et al., 2007), which, adjusted for the cost-of-living index, would in

152016 be equivalent to $131000 €$. Such expenses could lead parents to upgrade their

16 vocational aspirations (Self-Enhancement values). In a dual breadwinner society, such as

17 Finland, both parents may experience a conflict between focusing more on the child and less on themselves and their careers, and the need to economically provide for the child. Future research should investigate whether parenthood shifts women's values towards the SelfTranscendence in countries in which the male breadwinner family model is predominant.

Our results are consistent with the social role explanation offered by Milfont et 
1 Conservation values. That is, women entering parenthood may take on the majority of

2 parenting and housekeeping tasks, and this may affect the importance that they attribute to

3 Conservation values. Men's life priorities may simply not be that affected by changes in their

4 domestic situation (Ferriman et al., 2006). However, our results are also in no way

$5 \quad$ inconsistent with an ultimate evolutionary explanation for the observed sex difference.

6 Evolutionary theories suggest that concerns about the well-being and survival of offspring,

7 both of which could be expected to be served by the stability of the social environment,

8 should be higher for women than men (Buss, 2007).

Self- and spouse-ratings were in agreement that women, upon becoming

10 parents, moved towards greater Conservation over Openness to Change values. Regarding

11 men, the picture was more complex. Women perceived that their spouses' values had

12 changed in a fashion similar to their own values, but there was no evidence of change in new

13 fathers' self-reports. Furthermore, in the nationally representative sample (Study 1), there was

14 no association between fatherhood and Conservation values. That women assume their

15 spouse's to experience similar changes in values as they themselves experience is not

16 surprising - people tend to assume that others, including close others, are similar to

17 themselves, and this effect is particularly strong for values (Harinck, De Dreu, \& Van

18 Vianen, 2000). Interestingly, such an assumption of similarity could have dire consequences.

19 Having a child has been shown to predict declines in marital satisfaction (e.g. Doss, Rhoades,

20 Stanley, \& Markman, 2009) and new parents report increased amounts of conflict and

21 disagreement relative to before childbirth (e.g. Kluwer \& Johnson, 2007). Interpersonal

22 conflicts can often be characterized by differences in values (Harinck et al., 2000), and value conflicts tend to escalate easily, especially if they violate previous assumptions of value 
1 similarity (Kouzakova, Ellemers, Harinck, \& Scheepers, 2012). Among the underlying

2 causes of conflict and disagreement in new parents could be (i) that becoming a parent affects

3 the values of fathers and mothers differently and (ii) that mother's believe father's to have

4 changed in the same way that they themselves have changed.

It is worth noting that the effect sizes that we observed were relatively small.

6 Due to the large sample size of Study 1, some of the effects that reached conventional levels

7 of statistical significance, such as those pertaining to the Self-Transcendence vs. Self-

8 Enhancement dimension, were too small to be meaningfully interpreted. Fortunately, the

9 strongest effect observed in Study 1 - that parenthood is among women associated with

10 increased adherence to Conservation over Openness to Change values - was also the one

11 effect that was consistently supported by the results of Study 2. Nevertheless, although Study

122 supports the notion that parenthood may influence certain values (and not only the other

13 way around) two limitations warrant mention. Assessment of values initially occurred after

14 the women knew that they were pregnant. Ideally, this assessment would have occurred prior

15 to participants' knowledge of future parenthood. Another limitation was that we did not

16 include a control group, which rules out the possibility of definite causal conclusions.

Although entering motherhood was robustly associated with value change, the effects were rather weak. Longitudinal studies with larger sample sizes would be necessary to

19 investigate whether the change we describe is moderated by other individual differences. It

20 would also be highly informative to compare the present results with results obtained in

21 cultures in which motherhood could be expected to be a more life-course changing event. In

22 dual breadwinner societies such as Finland, in which becoming a housewife is very 
1 uncommon, the effects of entering motherhood may be attenuated as compared to societies in

2 which being a stay-at-home mother is the norm. 


\section{References}

3 Bardi, A., \& Goodwin, R. (2011). The dual route to value change: Individual processes and

4 cultural moderators. Journal of Cross-Cultural Psychology, 42, 271-287.

Bardi, A., Lee, J. A., Hofmann-Towfigh, N., \& Soutar, G. (2009). The structure of intraindividual value change. Journal of Personality and Social Psychology, 97, 913-929.

Baxter, J., Buchler, S., Perales, F., \& Western, M. (2014). A life changing event: First births and women's attitudes to mothering and gender divisions of labour. Social Forces, 93, 989-1014.

Buss, D. M. (2007). The evolution of human mating. Acta Psychologica Sinica, 39, 502-512.

Dobewall, H., Aavik, T., Konstabel, K., Schwartz, S. H., \& Realo, A. (2014). A comparison of self-other agreement in personal values versus the Big Five personality traits. Journal of Research in Personality, 50, 1-10.

Doss, B. D., Rhoades, G. K., Stanley, S. M., \& Markman, H. J. (2009). The effect of the transition to parenthood on relationship quality: an 8-year prospective study. Journal of Personality and Social Psychology, 96, 601-619.

Dunlap, William P.; Cortina, Jose M.; Vaslow, Joel B.; Burke, Michael J. (1996). Metaanalysis of experiments with matched groups or repeated measures designs. Psychological Methods, 1, 170-177. 
1 Gouveia, V. V., Milfont, T. L., \& Guerra, V. M. (2014). Functional theory of human values:

Testing its content and structure hypotheses. Personality and Individual Differences, 60, 41-47.

Gouveia, V. V., Vione, K. C., Milfont, T. L., \& Fischer, R. (2015). Patterns of value change during the life span: Some evidence from a functional approach to values. Personality and Social Psychology Bulletin, 41, 1276-1290.

Harinck, F., de Dreu, C. K. W., \& Van Vianen, A. E. M. (2000). The impact of conflict issues on fixed-pie perceptions, problem solving, and integrative outcomes in negotiations. Organizational Behavior and Human Decision Processes, 81, $329-358$.

Kartovaara, L., Rintanen H., Säkkinen, S., Reijo, M., Sauli, H., Rautanen, R., Reijo, M., Rintanen, H., Sauli, H., Säkkinen, S., Telasuo, C. (2007) Suomalainen lapsi 2007 (The Finnish child 2007). Helsinki, Finland: Statistics Finland

Katz-Wise, S.L., Priess, H.A. \& Hyde, J.S. (2010). Gender-role attitudes and behavior across the transition to parenthood. Developmental Psychology, 46, 18-28

Kluwer, E. S., \& Johnson, M. D. (2007). Conflict frequency and relationship quality across the transition to parenthood. Journal of Marriage and Family, 69, 1089 - 1106

Kouzakova, M., Ellemers, N., Harinck, F., \& Scheepers, D. (2012). The implications of value conflict: How disagreement on values affects self-involvement and perceived common ground. Personality and Social Psychology Bulletin, 38, 798-807.

Lindeman, M., \& Verkasalo, M. (2005). Measuring values with the short Schwartz's value survey. Journal of Personality Assessment, 85, 170-178. 
1 Maio, G. R. (2010). Mental representations of social values. Advances in Experimental Social Psychology, 42, 1- 43.

Milfont, T. L., Milojev, P., \& Sibley, C. G. (2016). Values stability and change in adulthood: A three-year longitudinal study of rank-order stability and mean-level differences. Personality and Social Psychology Bulletin, 42, 572-588.

Schwartz, S. H. (1992). Universals in the content and structure of values: Theoretical advances and empirical tests in 20 countries. In M. Zanna (Ed.), Advances in experimental social psychology (Vol. 25, pp. 1-65). New York, NY: Academic Press.

Schwartz, S. H. (2003). A proposal for measuring value orientations across nations. ESS Questionnaire Development Report (Chapter 7). Available from: http://www.europeansocialsurvey.org.

Schwartz, S. H. (2014). Functional theories of human values: Comment on Gouveia, Milfont, and Guerra (2014). Personality and Individual Differences, 68, 247-249.

Schwartz, S. H., \& Rubel, T. (2005). Sex differences in value priorities: Cross-cultural and multimethod studies. Journal of Personality and Social Psychology, 89, 10101028.

Tarkkonen, L., \& Vehkalahti, K. (2005). Measurement errors in multivariate measurement scales. Journal of Multivariate Analysis, 96, 172-189.

Verkasalo, M., Lönnqvist, J-E., Lipsanen, J., \& Helkama, K. (2009). European norms and equations for a two dimensional presentation of values as measured with Schwartz's 21-item portrait values questionnaire. European Journal of Social Psychology, 39, 780-792. 
1 Table 1. Means, Standard Deviations, Reliabilities, and Change Statistics for Self- and 2 Spouse-ratings of Personal Values.

\begin{tabular}{|c|c|c|c|c|c|c|c|c|c|}
\hline & \multicolumn{3}{|c|}{ Time 1} & \multicolumn{3}{|c|}{ Time 2} & \multicolumn{3}{|c|}{ Change Statistics } \\
\hline & $M$ & $S D$ & $G R C$ & $M$ & $S D$ & GRC & $d$ & $t(d f)$ & $p$ \\
\hline \multicolumn{10}{|l|}{ Women self-ratings } \\
\hline Conservation & -0.02 & 1.12 & .77 & .10 & 1.05 & .73 & -0.11 & $-2.37(132)$ & .02 \\
\hline Self-Transcendence & 0.32 & .86 & .71 & .32 & .92 & .76 & 0.00 & $-0.01(132)$ & .99 \\
\hline \multicolumn{10}{|l|}{$\begin{array}{l}\text { Women rated by } \\
\text { spouses }\end{array}$} \\
\hline Conservation & 0.16 & 1.23 & .75 & 0.31 & 1.27 & .71 & -0.12 & $-2.38(126)$ & .02 \\
\hline Self-Transcendence & -0.02 & 0.96 & .70 & -.06 & 1.03 & .67 & 0.04 & $0.66(126)$ & .51 \\
\hline \multicolumn{10}{|l|}{ Men self-ratings } \\
\hline Conservation & 0.12 & 1.13 & .72 & 0.15 & 1.07 & .81 & -0.03 & $-0.46(128)$ & .65 \\
\hline Self-Transcendence & .03 & 0.89 & .64 & -.02 & 0.91 & .75 & 0.06 & $0.80(128)$ & .42 \\
\hline \multicolumn{10}{|l|}{$\begin{array}{l}\text { Men rated by } \\
\text { spouses }\end{array}$} \\
\hline Conservation & 0.26 & 1.01 & .77 & 0.41 & 1.01 & .73 & -0.15 & $-2.07(123)$ & .04 \\
\hline Self-Transcendence & 0.36 & 0.96 & .71 & 0.24 & 0.93 & .76 & 0.13 & $1.63(123)$ & .11 \\
\hline
\end{tabular}


1 Figure Captions.

2 Figure 1. Schwartz's model of the relations between values. Note: From "Universals in the 3 context and structure of values: Theoretical advances and empirical tests in 20 countries," by

4 S. Schwartz, 1992, Advances in Experimental Social Psychology, 25, p. 45. Copyright 1992 5 by Elsevier. Adapted with permission. 